\title{
Anesthetic experience of a patient with tracheomegaly -A case report-
}

\author{
Mi Young Kim, Eun Joo Kim, Byung Woo Min, Jong Suk Ban, Sang Kon Lee, and Ji Hyang Lee \\ Department of Anesthesiology and Pain Medicine, Daegu Fatima Hospital, Daegu, Korea
}

Tracheomegaly or tracheobronchomegaly is a rare syndrome that consists of marked dilatation of the trachea and the major bronchi, and this is usually due to a congenital defect of the elastic and muscle fibers of the tracheobroncheal tree. Physicians have had only limited experience with performing anesthesia in patients with this type of syndrome. This syndorme is diagnosed by roentenological investigation and this condition is frequently associated with chronic respiratory infection and partial airway obstruction. In this report, we present a case of performing tracheostomy for a patient with tracheomegaly, and this was probably secondary to mechanical ventilator therapy. The regular tracheostomy tube did not provided sufficient length to allow the cuff to lie properly in the trachea in this patient. Because of the peri-cuff air leakgae and hypercapnea after tracheostomy, we needed a longer tracheostomy tube. But we didn't have such a tube and we didn't know any other method, so we couldn't perform tracheostomy. Therefore, we introduced a method of reducing the length of the endotracheal tube to a suitable size until a longer tracheostomy tube can be obtained for those patients having tracheomegaly. (Korean J Anesthesiol 2010; 58: 197-201)

Key Words: Tracheobronchomegaly, Tracheomegaly, Tracheostomy tube.

Tracheomegaly or tracheobronchomegaly (Mounier-Kuhn Syndrome) is a well-defined clinical and radiologic entity that's characterized by marked dilatation of the trachea and this is associated with Ehlers-Danlos syndrome, chronic smoking, chronic brochitis, pulmonary emphysema, cystic fibrosis and multiple chondritis, pulmonary fibrisosis [1]. It is characterized by dilatation of the trachea and recurrent pulmonary infection and secondary tracheomegaly can also develop due to mechanical ventilation. In this report, we present a case of an 81-year-old woman with tracheomegaly that was probably secondary to mechanical ventilator therapy and we attempted to perform tracheostomy. The regular tracheostomy tube did not provided sufficient length to allow the cuff to lie properly in the trachea in this patient. Because of the peri-cuff air leakage and hypercapnea after tracheostomy, we needed a longer tracheostomy tube, but we didn't have such a tube and we didn't know any other method, so we couldn't perform tracheostomy. So, we report on the case with a review of the related literature. a longer tracheostomy tube which has modified endotracehal tube mentioned at this case, may be an excellent substitute when a long tracheostomy tube is needed in an emergency for the patient who has an anatomic abnormality of the respiratory tract.

Received: June 26, 2009. Revised: 1st, July 9, 2009; 2nd, July 23, 2009. Accepted: July 30, 2009.

Corresponding author: Eun Joo Kim, M.D., Department of Anesthesiology and Pain Medicine, Daegu Fatima Hospital, 302-1, Sinam-dong, Dong-gu, Daegu 701-010, Korea. Tel: 82-53-940-7434, Fax: 82-53-954-7417, E-mail: kej1127@fatima.or.kr

(c)This is an open-access article distributed under the terms of the Creative Commons Attribution Non-Commercial License (http:// creativecommons.org/licenses/by-nc/3.0/), which permits unrestricted non-commercial use, distribution, and reproduction in any medium, provided the original work is properly cited. 


\section{Case Report}

A 81-year-old woman (height: $150 \mathrm{~cm}$, body weight: $49 \mathrm{~kg}$ ) was admitted to an intensive care unit because of respiratory failure and generalized edema. She was followed up in our hospital because of hypertension, congestive heart failure, asthma and a destroyed lung due to having pulmonary tuberculosis for 9 years. She was admitted in an intensive care unit and she received controlled mechanical ventilation because of the aggressive generalized edema and respiratory failure caused by the corpulmonale and congestive heart failure. The controlled ventilation was maintained with a tidal volume of 380-440 ml, a respiratory rate (RR) of $16-24 \mathrm{bpm}$ and an $\mathrm{FiO}_{2}$ of $35 \%$ and a positive end expiratory pressure (PEEP) of $5 \mathrm{cmH}_{2} \mathrm{O}$. She developed tracheomegaly during the 53 days of mechanical ventilation. She was impossible to wean off the mechanical ventilator, so she was planned to undergo tracheostomy. On the chest radiography, the maximum transverse diameter of the trachea was measured to be $50.3 \mathrm{~mm}$ (Fig. 1); on the thoracic $\mathrm{CT}$, the maximum diameter of the trachea was measured to be $51.3 \mathrm{~mm}$ and $48.8 \mathrm{~mm}$, respectively, in the sagittal and transverse directions (Fig. 2).

The patient was premedicated with $0.2 \mathrm{mg}$ of glycopyrrolate IM at 30 minutes pre-op. She was transported in the operating room and her trachea was intubated with a $6.5 \mathrm{~mm}$ internal diameter endotracheal tube. We connected the breathing circuits and the endotracheal tube, we monitored the electrocardiography and performed noninvasive blood pressure monitoring, pulse oximetry and capnography. At arrival in the operation room, the patients was drowsy and her vital signs were blood pressure: 130/80 $\mathrm{mmHg}$, heart rate: $130 \mathrm{rate} / \mathrm{min}$, $\mathrm{O}_{2}$ saturation: $72 \%$ and end-tidal carbon dioxide $\left(\mathrm{ETCO}_{2}\right): 56$

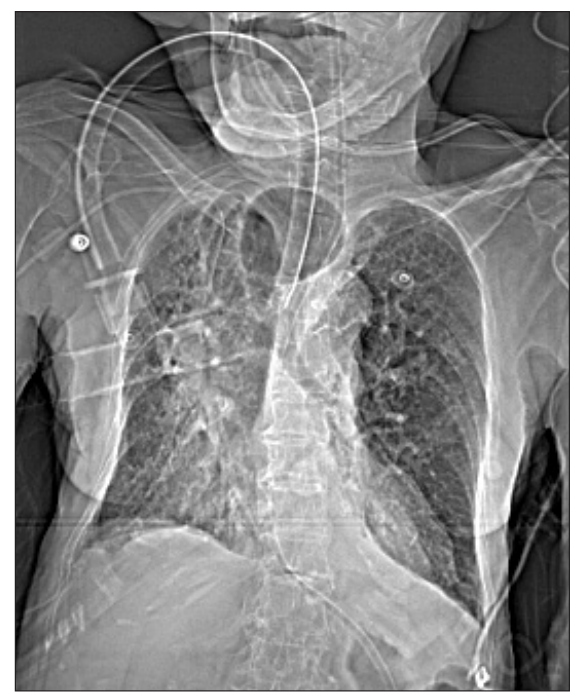

Fig. 1. Chest X-ray shows dilatation of the trachea at the cuff site.
mmHg. After hyperventilation by using ambu-bagging with $100 \% \mathrm{O}_{2} 6 \mathrm{~L} / \mathrm{min}$, the $\mathrm{O}_{2}$ saturation and $\mathrm{ETCO}_{2}$ reached $95-96 \%$ and $43-46 \mathrm{mmHg}$ respectively.

Anesthesia was induced with $5 \mathrm{mg}$ of midazolam IV and 15 $\mathrm{mg}$ of rocuronium bromide IV after loss of conscienceness and the $0.05-0.1 \mu \mathrm{g} / \mathrm{kg} / \mathrm{min}$ of remifentanil was continuously infused. Anesthesia was maintained with sevoflurane 1-1.5 Vol\%, The $\mathrm{FiO}_{2}$ was $60 \%$, and fresh oxygen was given at $4 \mathrm{~L} /$ min. Pressure controlled ventilation via a ventilator (Cato ${ }^{\circledR}$ edition, Dräger Medical AG, Germany) was provided with a peak airway pressure of $25 \mathrm{mmHg}$, The RR was $15-20 \mathrm{bpm}$ and the PEEP was $5 \mathrm{cmH}_{2} \mathrm{O}$. After tracheostomy, we extubated the endotracheal tube and then a $7 \mathrm{~mm}$ cuffed tracheostomy tube was inserted. We inflated the cuff with $10 \mathrm{ml}$ air via a pilot balloon of the tracheostomytube, but tidal volume was very small because of the significant peritubal leakage during the ambu-bagging. Despite of inflating the cuff with $15 \mathrm{ml}$ air via a pilot balloon, after the $8 \mathrm{~mm}$ tracheostomy tube re-intubated, we couldn't control the ventilation because of peritubal air leakage. The $\mathrm{ETCO}_{2}$ continued to increase to $55-60 \mathrm{mmHg}$.

The arterial blood gas showed severe hypercapnia: $\mathrm{pH} 7.09$, $\mathrm{PaCO}_{2} 97.2 \mathrm{mmHg}, \mathrm{PaO}_{2} 78 \mathrm{mmHg}$ and $\mathrm{HCO}_{3}{ }^{-} 29.7 \mathrm{mEq} / \mathrm{L}$. We observed the nasal and oropharyngeal air leakage, so we compressed the above site of the thyroid cartilage and we then confirmed the reduced air leakage. We packed the larynx with wet gauze using an intubating blade and forceps to prevent gas leakage. But the tidal volume was $100-150 \mathrm{ml}$ and air leakage was still present. To preventing laryngeal air leakage, we intubated with a 4 sized Proseal ${ }^{\circledR}$ laryngeal mask airway after sealing the connector with tape. We could control the ventilation as the the air leakage was reduced and tidal volume was more than $200 \mathrm{ml}$, so we brought the patient back to consciousness with $100 \%$ oxygen. At this point, the patient's

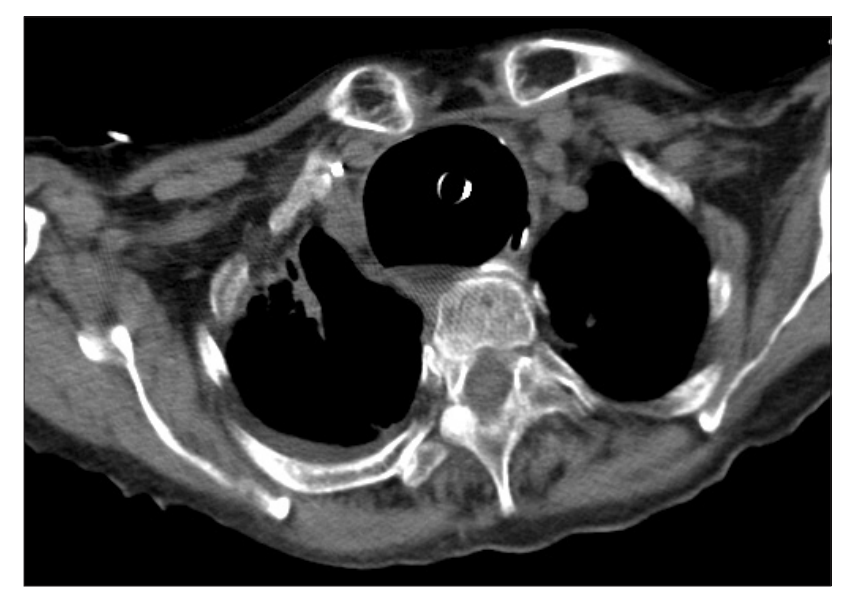

Fig. 2. Chest CT scan in axial plane shows marked tracheal dilatation at the cuff site. Tracheal tube in the centre. 
vital signs were: blood pressure: 100/70 $\mathrm{mmHg}$, heart rate: 100-110 rate/min, $\mathrm{O}_{2}$ saturation: $95-96 \%, \mathrm{ETCO}_{2}: 43 \mathrm{mmHg}$. But as the patient awoke and she recovered her laryngeal reflex, the laryngeal mask airway was displaced, so we couldn't controlled the ventilation. Once more the $\mathrm{ETCO}_{2}$ increased to $55-60 \mathrm{mmHg}$, and we planned endotracheal reintubation. After IV midazolam $3 \mathrm{mg}$ and remifentanil $60 \mu \mathrm{g}$, the tracheostomy tube was extubated. We intubated her with a $6.5 \mathrm{~mm}$ endotracheal tube and inflated the cuff to $25 \mathrm{cmH}_{2} \mathrm{O}$ with a cuff pressure manometer (VBM Medizintechnik GmbH, Germany). The endotracheal tube depth was $23 \mathrm{~cm}$ at the patient's upper lip. Chest auscultation revealed symmetrical and little air leakage was present. But the tidal volume measured over 300 $\mathrm{ml}$ for ambu-bagging. The incision site of the tracheostomy was sutured. After hyperventilation with ambu-bagging, the $\mathrm{ETCO}_{2}$ measured 38-42 mmHg. The arterial blood gases were a pH of 7.29, a $\mathrm{PaCO}_{2}$ of $46.2 \mathrm{mmHg}$, a $\mathrm{PaO}_{2}$ of $78 \mathrm{mmHg}$ and a $\mathrm{HCO}_{3}{ }^{-}$of $29.7 \mathrm{mEq} / \mathrm{L}$. The patient's vital signs were a blood pressure of 105/40 $\mathrm{mmHg}$, a heart rate of 105 beats/min and an $\mathrm{O}_{2}$ saturation of $97 \%$. The patient was moved ICU with ambubagging while she was unconscience.

\section{Discussion}

Tracheomegaly was first recognized at autopsy by Czyhlarz in 1897, but it was not until 1932 that Mounier-Kuhn associated the endoscopic and radiographic appearances [2]. In Korea, tracheobronchomegaly with multiple diverticula was first reported by Park et al. in 1993 [3]. Tracheomegaly is diagnosed when the transverse diameter of the trachea is greater than normal and exceed $25 \mathrm{~mm}$ and $21 \mathrm{~mm}$ in men and women, respectively. The internal transverse diameter of the trachea is measured $2 \mathrm{~cm}$ above the top of the aortic arch on the posteroanterior chest radiographs [4]. Normally, the transverse diameter measures $13-25 \mathrm{~mm}$ in men and 10-21 $\mathrm{mm}$ in women. On simple chest radiographs, we identified the increased diameter of the central trachea, which is more easily observed on the lateral view than the posteroanterior view. The diameters of the trachea $2 \mathrm{~cm}$ above the top of the aortic arch, the right main bronchus and left main bronchus that exceed $3 \mathrm{~cm}, 2.4 \mathrm{~cm}$ and $2.3 \mathrm{~cm}$ respectively, on the standard chest radiographs or bronchogram are diagnostic of tracheobronchomegaly. For chest CT, these values are $3.0 \mathrm{~cm}$, $2.0 \mathrm{~cm}$ and $1.8 \mathrm{~cm}$, respectively [3]. In this report, the maximum transverse diameter of the trachea was measured to be $50.3 \mathrm{~mm}$ on chest radiography (Fig. 1). For chest CT, these values are 51.3 $\mathrm{mm}$ and $48.8 \mathrm{~mm}$, respectively, in the sagittal and transverse directions (Fig. 2). The transverse diameters of the right and left main bronchi were $1.5 \mathrm{~cm}$ and $1.3 \mathrm{~cm}$, respectively, and this wasn't appropriate for tracheobronchomegaly.
The symptoms of tracheomegaly are nonspecific with fever, chilling, cough and sputum production secondary to bronchiectasis and lower respiratory infection. The grossly enlarged, but weakened airways and inefficient cough mechanisms block mucocilliary clearance leading to mucous retention with resultant recurrent pneumonia, bronchiectasis and fibrosis. Excessive sputum production with occasional hemoptysis occurs and the patients may develop dyspnea and respiratory failure as the lungs become progressively damaged. In addition, spontaneous pneumothorax, hemoptysis, pneumonia and finger clubbing may develop [5]. The pulmonary function tests reveal an obstructive pattern and restrictive ventilatory impairment when the fibrosis progresses. In this case, the pulmonary function tests were not obtained because the patient had received mechanical ventilation since her admission. Tracheomegaly should be diagnosed before an operation, but it can appear in patients with no symptoms and because the air leaks a lot during the induction of anesthesia induction from a patient who has previously received radiation therapy to the head and neck. There has been a case in which the doctor discovers tracheomegaly after excluding injury due to the cuff or other problems during recurrent intubation [6]. Thus, the anesthesiologist must consider the problems of respiratory tract, including tracheomegaly, for patients with these types of medical histories.

The etiology of this is various. Autopsy studies have suggested a congenital defect or atrophy of the elastic and smooth muscle tissues of the trachea because of the reports of associated connective tissue disease such as Ehlers-Danlos syndrome and dermatochalasis [4]. However, some physicians have suggested tracheomegaly's secondary development by ventilator therapy, barotrauma, smoking and chronic irritants because most patients have no other connective tissue abnormality and tracheomegaly is discover after the second decade of life [7]. Acquired tracheomalacia may be caused by pressure necrosis, impairment of the blood supply, infection and the cyclic friction on the dry tracheal mucosa during prolonged endotracheal intubation. Some may develop tracheomegaly [8]. In this case, our patient developed tracheomalacia from the recurrent inflammation and infection due to chronic bronchitis and emphysema. During the mechanical ventilation, pressure on the tracheal wall during prolonged endotracheal intubation would help develop the secondary tracheomegaly.

It is said that tracheomegaly frequently occurs when the period of pulmonary fibrosis is long and the respiratory pulmonary disease is severer, and the main mechanism for the occurrence of tracheomegaly with diffuse pulmonary fibrosis is the traction on the tracheal wall [9]. The prevalence factor of tracheal traction that increases the is the increase in the elastic recoil pressure that occurs due to the abnormal increase of the 
fibrosis tissue at the lung parenchyma. Pulmonary fibrosis does not invade the respiratory tract itself, but rather, it increases the elastic recoil pressure, and so it pulls the respiratory tract and causes tracheomegaly [4]. Tracheal stenosis also causes tracheomegaly with the increase of the elastic recoil pressure for the triggers of the tracheal traction [9]. This may cause tracheal stenosis or aggravation of tracheomegaly as a complication of endotracheal intubation for tracheobronchomegaly, while reporting the increase in enlarged trachea after intubating, using the tube with cuffs for the patient who suffers from tracheobronchomegaly, so Messahel said that, in case mechanical ventilator therapy is needed, the method to charge the throat with wet gauze to reduce the leakage of anesthesia gas and danger of inhalation and to use the endotracheal tube with no cuff is recommended [10]. However, Bourne, et al used the endotracheal tube of a bit larger diameter with cuffs for the patient with abnormally large diameter of trachea because, although the cuff is inflated in maximum in case the diameter of trachea is considerably large, there is a danger of pulmonary aspiration due to severe air leakage around the cuff [11]. According to the report of intubation for general anesthesia of other patients of tracheomegaly abroad, $9.0 \mathrm{~mm}$ endotracheal tube was used for the patient whose transverse diameters are $34 \mathrm{~mm}$ by standard chest radiography and $18 \mathrm{ml}$ of air was inflated into the cuff for the air not to leak around the cuff so that operation worked well [12].

The patient of this case had maximum diameter of trachea, which was $51.3 \mathrm{~mm}$ by chest CT. According to the report by Balakrishnan et al., who measured tracheal diameter by chest CT targeting 5,324 patients who had abnormal simple chest radiography and respiratory problem, the patient had very large diameter of trachea comparing with the maximum diameter

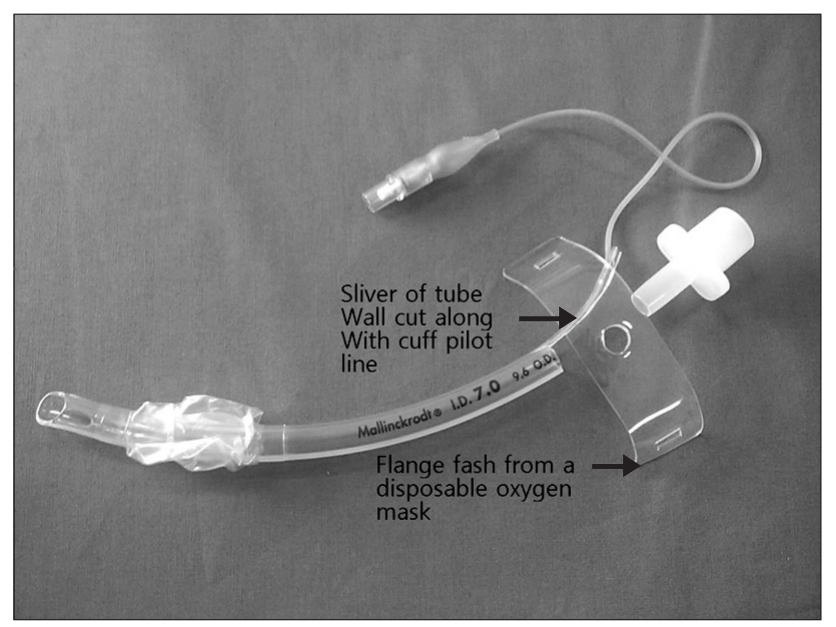

Fig. 3. Components of the modified tracheostomy tube. of trachea $35.72 \mathrm{~mm}$ of the patient who had the largest trachea [13]. Owing to this, the patient of this case was impossible to controlled ventilation by inflating the cuff simply due to the severe air leakage. However, the control of ventilation was possible by fixing through the spot which passed the broadest space of the trachea but not passing the carina, utilizing the fact that tracheomegaly was not severe $2-3 \mathrm{~cm}$ up from the carina. However, general tracheostomy tubes of $7 \mathrm{~mm}$ and $8 \mathrm{~mm}$ are limited in intubation depth by $80 \mathrm{~mm}$ and $90 \mathrm{~mm}$ in total. After all, the patient got severe hypercapnia by planning the surgery, not perceiving the necessity of a longer tracheostomy tube.

Besides its average size, the tracheostomy tube is commercialized by extra-long one (TRACOE ${ }^{\circledR}$ medical GmbH, Germany). In case of $7 \mathrm{~mm}, 8 \mathrm{~mm}$ tracheostomy tubes, the total lengths are $104 \mathrm{~mm}, 120 \mathrm{~mm}$, and in case of $10 \mathrm{~mm}$ tracheostomy tube, the total length is $135 \mathrm{~mm}$. Long tracheostomy tube is needed when there is anatomic abnormality such as a very thick neck or tracheal stenosis or enlargement, but it is seldom used, so the hospital usually doesn't have it. As the patient is limited in movement of neck, Hydri et al., has reported the method to use while transforming the endotracheal tube and, although there may be methods to use by intubating the endotracheal tube in the tracheostomy incision site until these patients secure long tracheostomy tube, it has no good appearance and has concerns of extubation [14].

This hospital also could make a long tracheostomy tube which has modified endotracheal tube while connecting endotracheal connector, cutting the disposable oxygen mask, and inserting neck flange into the endotracheal tube after cutting the inflation line which swells the pilot balloon of the endotracheal tube by deciding the size for the patient not being damaged (Fig. 3). Modified tracheostomy tube is longer than the general ones,

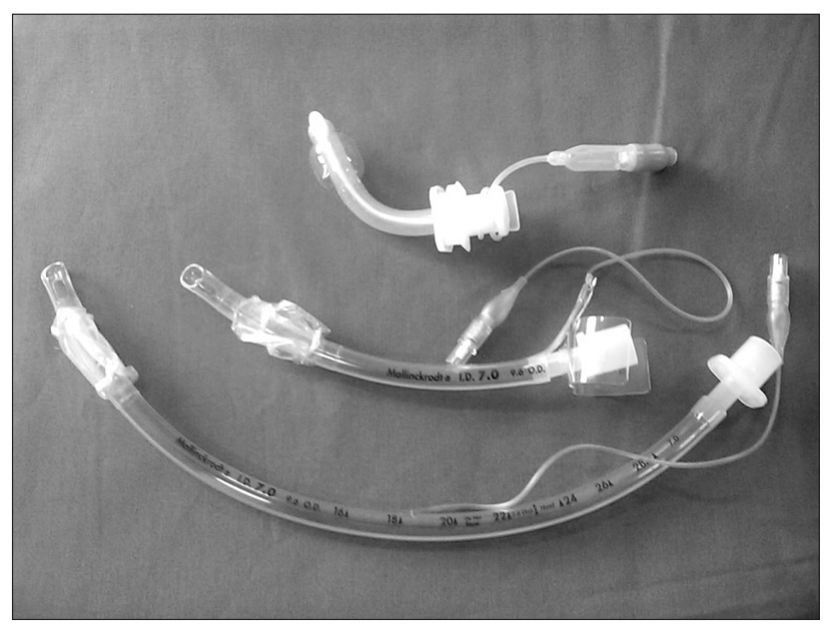

Fig. 4. A visual comparison between regular tracheostomy tube, the modified long tracheostomy tube and endotracheal tube. 
and is surely shorter than the endotracheal tube (Fig. 4).

In this case, it has considered intubating the endotracheal tube during the surgery instead of tracheostomy tube, but it was not attempted, considering the high risk of extubation by unstable fixation of endotracheal tube and the endotracheal tube being long. Through this case, the modified tracheostomy tube reformed by this endotracheal tube is thought as an excellent substitute until the long tracheostomy tube is secured during the emergency.

This case was diagnosed as tracheomegaly, but after tracheostomy, it has not predicted the situation that it isn't ventilated as a general tracheostomy tube, and it was a considerably embarrassing experience of a view on hypercapnia and acidosis. In case of patient of general tracheomegaly, as the size of the trachea was not severe, could managed the airway only by inflating the cuff. But, as in this case, there may be a situation at which the airway cannot be managed only by inflating the cuff for the patient of very large tacheomegaly. Also, in case of regular tracheostomy tube, its length is limited, so the length of intubation is uncontrollable.

So, when planning the surgery of a patient with tracheomegaly, enough consideration for the diameter of trachea at the spot where endotracheal tube and tracheostomy tube are located will be needed. A longer tracheostomy tube, which has modified endotracehal tube mentioned at this case, may be of help in managing the airway by the anesthegiologist when a long tracheostomy tube is needed in emergency for the patient who has anatomic abnormality of the respiratory tract unpredicted such as tracheomegaly, thick neck and tracheal stenosis, which are not diagnosed yet.

\section{References}

1. Breatnach E, Abbott GC, Fraser RG. Dimensions of the normal human trachea. AJR Am J Roentgenol 1984; 142: 903-6.

2. Mounier-Kuhn P. Dilatation de la trachee: constatations radiographiques et bronchoscopiques. Lyon Medical 1932; 150: 106-9.

3. Park CS, Kim JS. Tracheobronchomegaly with multiple diverticula: a case report. J Korean Radiol Soc 1993; 29: 99-103.

4. Woodring JH, Barrett PA, Rehm SR, Nurenberg P. Acquired tracheomegaly in adults as a complication of diffuse pulmonary fibrosis. AJR Am J Roentgenol 1989; 152: 743-7.

5. van Schoor J, Joos G, Pauwels R. Tracheobronchomegaly: the Mounier-Kuhn syndrome: report of two cases and review of the literature. Eur Respir J 1991; 4: 1303-6.

6. Parris WC, Johnson AC. Tracheomegaly. Anesthesiology 1982; 56: 141-3.

7. Shin MS, Jackson RM, Ho KJ. Tracheobronchomegaly (MounierKuhn syndrome): CT diagnosis. AJR Am J Roentgenol 1988; 150: $777-9$.

8. Griscom NT, Vawter GF, Stigol LC. Radiologic and pathologic abnormalities of the trachea in older patients with cystic fibrosis. AJR Am J Roentgenol 1987; 148: 691-3.

9. Feist JH, Johnson TH, Wilson RJ. Acquired tracheomalacia: etiology and differential diagnosis. Chest 1975; 68: 340-5.

10. Messahel FM. Tracheal dilatation followed by stenosis in MounierKuhn syndrome. Anaesthesia 1989; 44: 227-9.

11. Bourne TM, Raphael JH, Tordoff SG. Anesthesia for patient with tracheobronchomegaly (Mounier-Kuhn syndrome). Anesthesia 1995; 50: 545-6.

12. Collard P, Freitag L, Reynaert MS, Rodenstein DO, Francis C. Respiratory failure due to tracheobronchomalacia. Thorax 1996; 51: 224-6.

13. Menon B, Aggarwal B, Iqbal A. Mounier-Kuhn syndrome: report of 8 cases of tracheobronchomegaly with associated complications. South Med J 2008; 101: 83-7.

14. Hydri AS. A modified endotracheal tube serving as a long tracheostomy tube. The Internet Journal of Otorhinolaryngology. 2007; 6(1). Available from http://www.ispub.com/journal/the_internet_ journal_of_otorhinolaryngology/volume_6_number_1_18/article/ a_modified_endotracheal_tube_serving_as_a_long_tracheostomy_ tube.html 